\title{
IAMJ
}

INTERNATIONAL

AYURVEDIC

MEDICAL JOURNAL

Review Article

ISSN: 2320-5091

Impact Factor: 6.719

\section{MENSTRUAL HYGIENE AND COMMON ADOLESCENT GYNECOLOGICAL PROBLEMS - A BIRD'S EYE VIEW}

\section{$\underline{\text { Anoop A K }}^{1 *}$, Arun Vaidya ${ }^{2}, \underline{\text { Athira Mohan M.O }}^{3}$}

${ }^{1} \mathrm{Ph} . \mathrm{D}$. Scholar, Department of Samhita and Siddhant, Parul Institute of Ayurved, Parul University, Vadodara, Gujarat, India,

${ }^{2}$ Professor, Department of Samhita and Siddhant, Parul Institute of Ayurved, Parul University, Vadodara, Gujarat, India,

${ }^{3}$ House Surgeon, VPSV Ayurveda College Kottakkal, Malappuram, Kerala, India

Corresponding Author: dranoopak86@gmail.com

https://doi.org/10.46607/iamj3209122021

(Published Online: December 2021)

Open Access

(C) International Ayurvedic Medical Journal, India

Article Received: 30/11//2021 - Peer Reviewed: 10/12/2021 - Accepted for Publication 11/12/2021

Check for updates

\begin{abstract}
Menstrual disorders are a common problem in adolescents the world over. Though the onset of menstruation is part of the normal maturation process, Menstrual disorders form the commonest gynecological complaint (45-58 \%) among adolescents. The series of natural changes occurring to the uterus and body starting from the first day(1) of periods until the day before next periods can be called as menstrual cycle. It consists of "menstruation" in which inner layers of uterus sheds along with blood, and "ovulation" in which the ovum is released from the ovary. Menstrual hygiene deals with special healthcare needs and requirements of women during monthly menstruation or menstrual cycle. Unhygienic menstruation is the prime cause of menstrual diseases. Abnormalities in menstrual cycle are increased or decreased menstrual flow and increased or decreased intervals between two menstrual cycles. Menstrual abnormalities are common pathological problems associated with women of puberty age, which is enhanced by disturbed dietary and daily regimens. It requires early attention and interventions to protect them from having undesired health events in the future. In addition to this appropriate Ayurveda medicines are required to bring the body in a balanced state. Here an attempt is made to compile the ideas of Acharya about menstrual health problems for their proper understanding and treatment through Ayurveda- the science which survived the time.
\end{abstract}


Keywords: Normal menstruation, Menstrual hygiene, Adolescent girls, Menstrual disorders, Treatment and prevention, Ayurveda, Ritu

\section{INTRODUCTION}

Menstrual disorders are common problems in adolescents the world over. Though the onset of menstruation is part of the normal maturation process, Menstrual disorders form the commonest gynecological complaint (45-58\%) among adolescents ${ }^{(1,2)}$.

The series of natural changes occurring to the uterus and body starting from the first day of periods until the day before the next periods can be called the menstrual cycle. It consists of "menstruation" in which inner layers of the uterus are shed along with blood and "ovulation" in which ovum is released from the ovary. It is a general opinion that menstruation usually occurs once a month. But in most people, it occurs as a cycle of 25- 32 days in length. The menstrual cycle is usually 28 days, measured by the time between the first day of one period and the first day of the next. The duration of bleeding is about 3-5 days and estimated blood loss is between 50 and $200 \mathrm{ml}$. The regular cycle of 28 days is seen only in a small proportion of women. A deviation of 2 or 3 days from the 28- day rhythm is quite common. The menstrual rhythm depends on the hormonal status of the Hypothalamo- pituitary- ovarian axis whereas the amount of blood loss depends upon the uterine condition ${ }^{(3)}$.

Menstruating women used to go through explosive circumstances within her body and mind. Some women experience difficulties like tolerable pain over the lower abdomen and low back, nausea, bloating, breast tenderness, a manifestation of acne along psychological and emotional disturbances.

\section{Menstrual hygiene}

Unhygienic menstruation is the prime cause of menstrual diseases. Moreover, it is during this period a woman is regarded most vulnerable for developing any kind of reproductive tract infections, urinary tract infections, and various sexually transmitted diseases. Menstrual hygiene deals with special healthcare needs and requirements of women during monthly menstruation or menstrual cycle ${ }^{(4)}$.
Unfortunately, due to lack of knowledge on menstruation, preparedness, and management or due to shyness end embarrassment, the situation becomes worse for them ${ }^{(5)}$.

Changing sanitary pads at regular intervals is the first thing to care about. Usually, 2-3 sanitary pads are required during the first 2 days of menstruation. Thereafter less than 2 sanitary pads are enough since the bleeding starts to diminish. A fully soaked sanitary pad consists of $5 \mathrm{ml}$ blood. Therefore a total of 7- 16 or an average of 10 sanitary pads are required for a single menstrual cycle. It should be changed every 4-6 hours Even though there is a less direct impact, it is our social responsibility to properly dispose of sanitary napkins. Inner garments should be washed and dried in sunlight. By doing so, fungal infections and itching caused by wet garments can be avoided. It is desirable to bathe in lukewarm water to ensure body hygiene. Since cold water interrupts the natural flow of blood, it is desirable to use warm water for a bath. Fiber and nutrient-rich, easily digestible foods are recommended during and a few days before menstruation along with that drinking plenty of water is essential. By doing so, difficulties during a menstruating period can be avoided to an extent.

Rest is very important during menstruation. The excess body strain interferes with the normal downward flow of menstruation. Studies show that this may cause diseases like endometriosis where tissue similar to the lining of the uterus grows outside the uterus, causing pain during menstruation and /or infertility ${ }^{(6)}$. The 7 days of rest followed conventionally by women appear to be scientific in this aspect ${ }^{(7)}$.

The very first menstruation is called menarche. After the first menstrual period, it takes at least 1-2 years for menstruation to return to normal. In some women, it may even regulate quickly. As mentioned earlier, it depends on the hormonal status of hypothalamo pituitary ovarian axis and the growth of the uterus. The time taken for this will be different for each person. The 
menstrual disorders that occur after the onset of regular menstruation need to be addressed with care. This is the first step in preventing problems like menstrual diseases and infertility in the future.

\section{Irregular Menstruation}

Abnormalities in the menstrual cycle are increased or decreased menstrual flow and increased or decreased intervals between two menstrual cycles. The symptoms can be

- Prolonged heavy bleeding

- Increased pain and cramps during menstruation

- Intermittent menstrual bleeding

- Absence of menstruation

- Infrequent menstruation

Along with these symptoms, some may experience obesity, increased hair growth in the face, chest and increased facial acne. Except for the absence of menstruation, all other symptoms among them are the initial complaints of girls. However, teenaged girls deliberately ignore amenorrhoea that is caused due to physical and mental stress. Hence there should be parental care towards symptoms and thus early management is necessary.

Other medications, climate changes, mental stress, long journeys etc causes menstruation either early or late. This can only be temporary, when the person comes back to a normal physical and mental state this will also come to normal without any proper medication. However, if these symptoms become chronic and affect the health and day to day activities proper medication and treatment should be needed.

The main reasons for these types of menstrual problems are:

- Increased and consistent mental stress

- Changed lifestyles

As far as concerned with the teenaged girls the reasons are stress and strain they face in this competitive world of education, especially because of the selfishness of parents to make their child first among others. This mental stress will be way beyond imagination and expressed in the form of defective sleep, imbalance of hormonal equilibrium and health. This kind of defect is visible in hostels where entrance coaching students are staying. Parents should take good care to avoid mental stress by engaging them in music, yoga, meditation, exercise, etc. along with the studies.

Another real cause we are facing changes in the lifestyle.

Nowadays teenagers are heavily practicing junk foods and fast foods which indeed cause no problem if we practice once in a while, but continuous consumption causes health issues and also menstrual problems.

Among the reasons, we can't go without mentioning the untimely intake of food. Late breakfast or skipping of breakfast may result in thyroid problems also latenight food or avoiding food at night should also be discouraged by the parents, because it may cause digestive problems along with menstrual ones.

Sleepless nights also lead to an imbalance of the biological rhythm of the body, of which the main reason is the glowing displays of Mobile phones.

Those who postpone the menstruation for silly reasons by medicinal intake usually get affected with menstrual problems, also those who suppress their urges like urination and defecation may result in menstrual problems especially painful menstruation.

Another reason explained here is the lack of exercise. Usually walking is preferred by people but nowadays it was overtaken by two-wheelers and buses etc. Also, the school-going children have kept away themselves from household activities in the name of studying, thus they may become obese. Obesity not only causes menstrual problems but also may cause infertility ${ }^{(8)}$.

Hence for a healthy mind and physique changes should be started from our day-to-day habits.

\section{Delayed Menarche}

If the girl is not attaining menstruation even after the age of 16 should have to consult a gynecologist.

Incomplete development of the uterus, blockage in the passage of the vagina, genetic abnormalities, etc. are some of the reasons for this.

\section{Premenstrual Symptoms}

Before attaining menstruation there are some physical and mental changes due to hormonal functions in the body. Pain over breasts, edema in the body, constipation, diarrhoea, excessive sweating, anxiety, anger, depression, etc. are some common symptoms seen before menstruation. But if these symptoms are excessive and 
intolerable which affects day-to-day activities, then one should go for proper medication.

Excessive Bleeding (menorrhagia, metrorrhagia, menometrorrhagia)

We have already dealt with normal menstrual bleeding. Apart from that heavy bleeding which may cause usage of more than 4 pads/day or duration of bleeding exceeds 7 days, then that can be counted as excessive bleeding. In such conditions amount of bleeding is usually more than $80 \mathrm{ml}$.

Along with bleeding if pallor, tiredness, fatigue, palpitation etc are seen should go for immediate treatment. Inadequate bleeding (Hypomenorrhoea)

Pallor is the main cause of this condition. Normal menstruation is regulated by proper management of pallor. Polycystic ovarian disease (PCOD)

Changes in the structure and functions of the ovary are the main reason for this. It leads to irregular menstruation by affecting the production of hormones. The main reason behind this is unhealthy food habits and lifestyle changes. This is more of a lifestyle disease than a menstrual disease, inadequate, excess or irregular menstruation, absence of menstruation for 2-3 months, blackish discolouration over the nape of the neck, hair growth similar to men over face, chest, and excessive acne vulgaris are the main signs and symptoms. This can be diagnosed by USG. This is to be treated in the initial stage itself along with proper medication proper exercises also to be done for better management. It reminds us never to treat this disease lightly as it can lead to infertility in the future.

\section{Dysmenorrhea}

Painful menstruation is one of the most common health problems in adolescents.

It is of 2 types

- Primary dysmenorrhea

- Secondary dysmenorrhea

Primary Dysmenorrhea:

Mostly seen in adolescents. Pain begins only after menstrual bleeding and is persistent until most of the blood is expelled out. This pain lasts for only 1-2days or 1-2hours and then subsides. There is no specific cause for this pain. There are no abnormalities found in USG or another diagnostic tool.

\section{Secondary Dysmenorrhea:}

This is caused by some underlying pathology. In such cases, menstrual pain begins 1-2 days before menstruation and lasts for the entire period. Uterine fibroids, endometriosis and adenomyosis are the root cause of this. This is diagnosed by sonography, laparoscopy etc. The contractions and relaxation of muscles in the lining of the uterus or momentum results in the expulsion of menstrual bleeding. Cramping pain during menstruation due to contraction and relaxation of this muscle can be seen in everyone.

In dysmenorrhea, such contraction and relaxation do not occur regularly. Unbalanced and strong contractions cause excruciating pain. Such Unbalanced contractions are due to underlying disease. So, if those diseases are treated effectively the issue can be resolved. In Primary dysmenorrhea, such contraction occurs for no apparent reason. Therefore, only analgesics are used to treat the disease in the modern system of medicine.

\section{Leucorrhea}

It is a common complaint raised by adolescent girls. Because of the unawareness, most of them can not differentiate the facts and fallacies regarding leucorrhea and vaginal discharge. As the name suggests, the discharge is white or yellowish-white in colour. It is normal to have whitish, non-slimy, moderate whitish discharge; from 8-14days of menstruation and slimy, whitish, moderate discharge from 14-21 days of menstruation.

It is caused by the action of female hormones in the first and second half of menstruation. Most people mistakenly think of it as s disease. It is only when this discharge becomes excessive and uncomfortable that is when the undergarments get wet or there is a need to wear sanitary pads, then it is called leucorrhea. In adolescents, it is due to an increase in the number of small blood vessels that form as a part of growth over the uterus, uterine tube and vagina. This lasts for a shorter duration. And it can be subsided by itself. Vaginal discharge is a different disease that is not seen in adolescents. Vaginal infection is the main reason behind this. It is especially found in married and sexually active women. Discharge was seen as yellowish, 
curdy, reddish with itching, burning and bad odour. Medical management should be necessary for this condition.

Adolescents also have a preconceived notion that itching, burning etc are symptoms of leucorrhea. Most children develop these symptoms due to urinary tract infections. This is mostly seen in children with a lack of drinking water and habitual suppression of urine. So, drinking plenty of water and practice of good toileting habits are also recommended.

\section{DISCUSSION}

The main thing we arrive at when we are worried about future survival is the prime importance of the health of adolescent girls. So, it is our duty to be concerned about them.

Ayurveda the science that lasts for ages also do concern about this. So, it explains such things in great detail. There are descriptions about ashta arthava dushti, vimsathi (Twenty) yonivyapath etc. The causes of these also point to the same directions where modern science reached recently such as mithya ahara vihara (abnormal diet and abnormal mode of living), pradushta arthava (irregularities of ovarian hormones and gonadotropins), beeja dosha (congenital anomalies) and daiva (idiopathic) ${ }^{(9)}$.

Let's codify the comments of acharyas under some familiar headings.

Menstrual disorders related to pain consists of $U d a$ varthini, Pariplutha, Vathaja arthava dushti, kashta arthava (which can be correlated with Dysmenorrhoea), Prakcharana (symptoms suggestive of low backache due to gynaecological origin), Viplutha (consists of chronic pelvic pain) etc. All these suggest the normalisation of deranged vata as the treatment. So sneha sveda (oleation and sudation), use of dravya which mitigate vata like dasamoola ksheera, bala etc. internally and as in the form of procedures like utharavasthi, anuvasana vasthi etc. (Ca chi 30) ${ }^{(10)}$ can be recommended.

The Acharya mentioned the condition of anarthava (amenorrhea) as a symptom complex in many gynecological disorders. For example vandhya (infertility), yonisosha( which is due to suppression of natural urges during menstruation), Shandi (compared to a genetic disorder characterized by anarthava and asthani), lohithakshaya (suggesting amenorrhea due to increased blood flow and characterized by karshya (emaciation) and vaivarnya (discoloration)), and Arajaska ( having similar symptoms of lohithakshaya). Specific treatments of each of them are described by assessing the nidana, samprapthi, and dosha lakshanas.

Hypomenorrhea is mentioned as arthava kshaya by acharya where yathochitha kala adarsanam (prolonged menstruation for more than one month), alpatha (scanty menstruation not lasting more than 3 days), and yoni vedana (pain in genital tract) are the main symptoms. For the treatment of them, the use of agneya dravya is suggested. It may include tila, masha, dadhi, matsya, kulatha, guda, japakusuma etc.

A few of the conditions due to infections and inflammations are pithala yoni vyapth, pariplutha etc. suggesting conditions like Pelvic inflammatory diseases which have a direct relationship with the regimen and food habits of a new era. The causes include increased intake of katu, amla, lavana, kshara and other pitha vridhikara nidana. Intake of sathavari and jeevaneeya ghritha are mentioned in the context of these diseases. Slaishmiki which shows kandu(itching) and pichila srava (mucoid discharge) also come under this category which can be correlated with vaginitis and needs the use of kapha hara dravya as oushadha.

Examples of Vaginal secretions and itching comprises diseases like Upaplutha which have todayuktha pandu and swetha srava (white and mucoid discharge with pain), acharana and viplutha characterized mainly by itching caused due to uncleanliness of the vagina.

\section{CONCLUSION}

Menstrual abnormalities are common pathological problems associated with women of puberty age, which is enhanced by disturbed dietary and daily regimens. It requires early attention and interventions to protect them from having undesired health events in the future. 
Indian system of medicine can do wonders through effective ayurvedic treatments in many of these conditions. In recognition of this, the Indian medical department is complementing a health plan called Rithu. The beneficiaries of this scheme are girls from selected schools in Kerala. They are provided with Ayurvedic guidelines for early detection and treatment of menstrual disease in children. It aims at creating awareness about lifestyle disorders among children and ensuring comprehensive health care through Ayurveda.

Menstrual disorders can be treated very effectively through Ayurveda. Menstrual blood is something that is expelled just like urine and faeces in our body. It requires the action of air moving downward in the body. Those who are accustomed to lack of exercise, untimely food habits, lack of sleep, unhealthy food habits mentioned before, suppression of urges results in abnormalities in functions of air moving downwards. Hence menstrual blood is obstructed in such cases. Most children are habituated to suppressing natural urges. So menstrual pain cannot be cured without changing the poor hygiene in the toilet at the school. So, it is understood that lifestyle corrections are mandatory for healthy periods.

In addition to this Ayurveda, medicines are required to bring the body in a balanced state. Along with that herbs, massage therapy, oil bath once in a week, yoga, and detoxifications measures as therapeutic modalities proper food habits through the concepts of Pathya and Apathya as per Ayurveda also help to prevent the prevalence of menstrual problems.

\section{REFERENCES}

1. Jacks TH, Obed JY Agida ET, Petrova GV. Dysmenorrhea and menstrual abnormalities among postmenarcheal secondary school girls in Maiduguri Nigeria.Afr J Med Med Sci.2005;34:87-9

2. Dutta R, Sengupta S. A profile of adolescent girls with gynaecological problems. J Obstet Gynecol India.2005;55:353-5

3. Padubidri VG, Shirish N Daftary. Hawkins \& Bourne Shaw's Textbook of gynaecology. Uttarpradesh; Elsevier a division of Reed Elsevier India Private Limited;2008; $14^{\text {th }}$ edition.p.41
4. Barathalakshmi J, Govindarajan PK, Ethirajan N, Felix AJ. Knowledge and practice of menstrual hygiene among school-going adolescent girls. Natl J Res Commun Med.2014; 3:138-42 [Google Scholar]

5. S. Nagar and K. R Aimol, "Knowledge of Adolescent Girls Regarding Menstruation in Tribal Areas of Meghalaya" Studies of Tribes and Tribals, Vol.8, no.1, pp.27-30, 2017.View at: Publisher site I Google scholar.

6. WHO definition of endometriosis https://www.who.int/definition of endometriosis dated 12/10/2021 time 12.08 am

7. Prof.K. R Srikantha murthy. Illustrated Susrutha samhitha of Acharya Susrutha, Sarirasthana. Vol1 (2/25). Varanasi; Choukhambha orientalia publishers;2016. pg.23

8. Zeynep Ozcan Dag and Berna Dilbaz, Impact of obesity on infertility in women J Turk Ger Gynecol Assoc.2015;16(2): 111-117.2015 Jun 1. [PubMed].

9. Dr R. K Sharma, Vaidya Bhagavan Dash.Agnivesa's Caraka Samhita, Chikitsasthana.Vol 5 (30/8). Varanasi; Chowkhamba Sanskrit series office:2018. pg.130

10. Dr R. K Sharma, Vaidya Bhagavan Dash.Agnivesa's Caraka Samhita, Chikitsasthana.Vol 5 (30/8). Varanasi; Chowkhamba Sanskrit series office:2018. pg. 128-221

\section{Source of Support: Nil Conflict of Interest: None Declared}

How to cite this URL: Anoop A K et al: Menstrual Hygiene And Common Adolescent Gynecological Problems - A Bird's Eye View. International Ayurvedic Medical Journal \{online\} 2021 \{cited December 2021\} Available from: http://www.iamj.in/posts/images/upload/3118_3123.pdf 